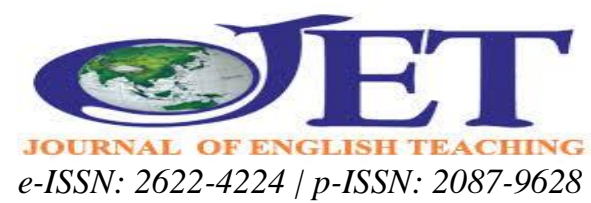

\title{
Interference of Compensatory Strategies in Oral Production of English Language Student in an ESL Classroom: Does Compensatory Strategy Play a Role in Academic Performance?
}

\author{
Novalyn M. Rubis \\ novalyn.rubis@deped.gov.ph \\ Isabela State University-San Mariano Campus, Philippines \\ Remart Dumlao \\ dumlaoremart25@gmail.com \\ MubanChombuengRajabhat University, Thailand
}

\begin{abstract}
The study aims to identify the compensatory strategies predominantly used by fifty-four ESL High school student, its relation to language proficiency level in terms of accuracy, fluency, and comprehensibility and to its role in academic performance of the participants. Two oral task namely oral interview and pictured-cued narration were used as primary source of data. The picture-cued narration was applied to determine the oral language proficiency level and compensatory strategies of the participants. Finding shows the eight compensatory strategies were employed in their production, namely, switching to mother tongue, getting help, using mime, selecting the topic, adjusting the message, coining words, avoiding communication partially and totally, and using circumlocution or synonyms. It was also found out that switching to mother tongue was predominantly employed in their oral production. There is, however, negative relationship between compensatory strategies used and academic performance of ESL learners. Pedagogical implications are discussed discussed in the paper.
\end{abstract}

Keywords: communicative competence, compensatory strategies, language classroom, oral production

\section{INTRODUCTION}

One important goal of language teaching is to develop the communication skill of learners (Dumlao \& Himmapan, 2018) to globally compete in the real world as English has been widely accepted as the most widespread language in the world. In the past decade, a growing body of research has focused on language learning strategies, however, not well familiar to some EFL and ESL language teacher. Language learning strategies ( hereto LLS), particularly in communicative competence are of interest not only for revealing the ways language learners apply learning strategies, but also for showing how the use of strategies is related to effective in target language learning (Oxford, 1990). Hence, this learning occurs and addresses in the English classroom, both language and content area teachers face problems regarding the use of English as the student's medium of communication particularly the student's inability to express themselves orally. It has been observed that when learners are asked to explain, discuss, converse or ask questions in English, they frequently stop speaking because they hardly know what to say. In this case, it seems problematic then which lead learners to find 
ways just to convey their ideas to other interlocutors. Learners rottenly find ways to fulfill the communicative goal; it is either they dispense with the original communicative goal which supposed to deliver, or they try and reach it via alternative plans just to convey their ideas, thus making use of the limited linguistic means they have at their disposal (Poulisse \& Schils, 1989). Further, this process would leads to a breakdown in communication, foreign language (FL) or second language (ES) learners generally manage to overcome their problems by employing one or more so-called compensatory strategies in communication (CSC). It is then believed that strategies used by successful learners may be learned by less successful learners, and language instructors can assist the language learning process by helping learners develop appropriate strategies.

\section{LITERATURE REVIEW}

A good number of studies on compensatory strategies and their relation to oral communication were also conducted in the past years. For instance, it was examined the impact of CS instruction in where a control and experimental groups received oral lessons. However, in addition to normal instruction, the experimental group received explicit training in strategies of resourcing, paraphrasing, repetition, fillers, selfcorrection, asking for clarification, and asking for confirmation. The results indicated that the experimental group outperformed the control group on the group discussion tasks. It was found that treatment had a positive impact on raising the awareness of the learners with respect to the range of communication strategies. While, In Chinese context, It was studied the gender effect on CS use among 36 Chinese EFL learners while they were performing oral and written communicative tasks. The participants were requested to communicate two abstract and two concrete concepts to a native speaker. They were not allowed to use the target words and were asked to interact with the native speaker till the native speaker could identify the target concept or the participant admit that they are unable to communicate. The analysis of the recorded interviews pointed to no differences between males and females in the use of CSs which was attributed to the learning environment. It was found that females were more efficient than males in their use of CSs because of the differences in their execution phase of the production. What makes conclusions difficult is the design of these studies and the type of tasks used; previous studies have not examined the effect of specific task type on CS use. Similarly, It was found out that although CS training has a significant effect on students" performance, the students use more CSs in the object description tasks than in the narrative tasks. Therefore, he suggested that different tasks elicit different CSs and multiple task types should be used in communicative classes .In another study on CS use in a task-based computer-meditated context, Smith (2003) concluded that task type influences compensatory strategy use. Since the participants employed more compensatory strategies in decision-making tasks, it was suggested that decision-making tasks may elicit more compensatory strategies than jigsaw tasks. Similarly, it was investigated types of communication strategies (CSs) employed by ESL students and the effects of task type and English speaking proficiency: high, middle, and low on their CS use.

These studies, however, restricted their scope within the frequency of the strategies and the role they play in communication process and in language acquisition. Hence, the present study aimed to identify the compensatory strategies predominantly used by ESL High school student in a public school and to determine the relationship 
between among the high school students" oral language proficiency, compensatory strategies, academic performance in English, and mother language. The results of this study may help ESL teachers in enhancing their students' oral communication skills and eventually make them full participating members of the language classroom as they use efficient compensatory.

\section{METHOD}

\section{Participants}

Thirty one male $(\mathrm{N}=31)$ and female ( $\mathrm{N}=23$ ) language learner ranging in a age from 10 16 years old participated in this research. All were enrolled in the course English 1a or Communication Arts 1 . Table 1 shows the participants profile and their language used.

Table 1:

\section{Participants Profile}

\begin{tabular}{|c|c|c|}
\hline \multirow[b]{2}{*}{ Personal profile } & \multicolumn{2}{|c|}{ Frequency } \\
\hline & $\mathrm{n}=54$ & Percent \\
\hline \multicolumn{3}{|l|}{ Mother Tongue } \\
\hline Ilocano & 37 & 68.52 \\
\hline Ibanag & 5 & 9.26 \\
\hline Ifugao, Ayangan, Kalinga, etc & 12 & 22.22 \\
\hline \multicolumn{3}{|l|}{ Language Spoken at Home } \\
\hline Ilocano & 24 & 44.44 \\
\hline Ibanag & 4 & 7.41 \\
\hline Ifugao & 8 & 14.81 \\
\hline Ilocano and Ifugao & 5 & 9.26 \\
\hline Ilocano and Tagalog & 8 & 14.81 \\
\hline Ilocano and Kalinga & 1 & 1.85 \\
\hline Ayangan & 1 & 1.85 \\
\hline Ibanag and Kalinga & 2 & 3.70 \\
\hline \multicolumn{3}{|c|}{ Language currently learning or recently learned } \\
\hline Ifugao & 9 & 16.67 \\
\hline English & 22 & 40.74 \\
\hline Tagalog & 15 & 27.78 \\
\hline Ibanag & 4 & 7.41 \\
\hline Ilocano & 4 & 7.41 \\
\hline \multicolumn{3}{|l|}{ Time spent for learning the language } \\
\hline 5 years and above & 13 & 24.07 \\
\hline 3 to 4 years & 14 & 25.93 \\
\hline 1 to 2 years & 14 & 25.93 \\
\hline Less than one year & 13 & 24.07 \\
\hline
\end{tabular}

It could be gleaned in Table 1 that majority of the 54 third year students are Ilocano with 37 or 68.52 percent, followed by Ifugao, Ayangan, Kalinga, etc. with 12 or 22.22 percent, and Ibanag, 5 or 9.26 percent. Meanwhile, Ilocano is the language spoken at home by 24 or 44.44 percent of the respondents, about 8 or 14.8 percent speak 
Ifugao, Ilocano- Tagalog, 5 or 9.26 percent speak Ilocano- Ifugao, 4 or 7.41 percent speak Ibanag, 2 or 3.70 percent speak Ibanag- Kalinga, and 1 or 1.85 speaks IlocanoKalinga and Ayangan. The table also shows that 14 or 25.93 percent of the respondents have 1 to 2 years ${ }^{\text {ee }}$ time spent for learning the language, and also 14 or 25.93 percent of the respondents spent 3-4 years in learning the language. Further, the table reveals that 13 or 24.07 percent of the respondents spent less than one year in learning the language and 13 or 24.07 of the respondents spent 5 years and above in learning the language.

Table 2:

Participants Academic Level

\begin{tabular}{ccl}
\hline Academic Performance level & $\begin{array}{c}\text { Frequency } \\
\mathrm{n}=54\end{array}$ & Percent \\
\hline 75-79 (below average) & 31 & 57.4 \\
80-85 (average) & 18 & 33.4 \\
$86-90$ (above average) & 5 & 9.5 \\
Total & 54 & 100 \\
\hline
\end{tabular}

It can be gleaned from the table that majority or 31 or 57.4 percent of the respondents belong to the "below average" level of academic performance, 18 or 33.4 percent was classified as "average" students, and 5 or 9.5 percent was categorized as "above averagee in the academic performance level.

\section{Instrument}

To gather pertinent background information, the participants were asked to fill up a questionnaire asking for their mother tongue (MT). To see the the compensatory strategies used by the participants, oral interview and a picture-cued narration were utilized. The oral interview consisted of 8-10 "wh" questions related to their personal background such as: (1) What is your favorite subject?; and(2) Why did you choose that subject?

Meanwhile, the picture-cued narration (PN) is to see how these compensatory strategies used in oral production and how respondent narrate the events that took in each picture. The PN consisted of six pictures in a series. The first one shows two painters wearing artist caps and artist outfit for painting. In the second picture, the note is blown away. In the third picture, a man holding a newspaper approaches the chair. The fourth picture shows a man sitting on the newly painted chair and reading his newspaper. In the fifth picture, a man stands up and notices that his coat is wet with paint. The last picture shows a man holding his coat and he is going to a dry cleaner.

To capture the transcriptions, a handy video camera was used. As the oral activities were being conducted, the researcher and the language teacher counted every compensatory strategy employed by each participant.

\section{Procedure}

The examination procedure consisted of preparing the needed instruments: interview guide, information sheet, and tally sheets for the oral interview, picture-cued narration, and compensatory strategies. The participants were scheduled for the oral tasks. To capture the transactions, a handy video camera was used. As the oral activities were 
conducted, the researcher and the language teacher who assisted her counted every compensatory strategy employed by each participant. To illustrate, if the participant code-switched and at the same time used another term in place of a more appropriate term, the strategy was counted and categorized as code-switching and synonym. For purposes of verification, the videotapes were viewed several times. The frequency of the compensatory strategies used in the actual task and in the video were carefully recounted and compared. It was noted that there was no case of differences in the coding and counting of the researcher and the language teacher who helped in the gathering and analysis of the data. Since the study focused on the use of compensatory strategy, gestures or nonverbal actions were assigned interpretations. The compensatory strategies that were used by the respondents during the interview and the picture-cued narration were clarified on the post consultation.

\section{Data Analysis}

Descriptive statistics such as frequency counts, percentages and means were used to describe the data gathered in this study. To determine the relationship among compensatory strategies and variables namely mother tongue and first grading grade in English Expressways II, Spearman"s coefficient of correlation (rho) was used. The significance level was tested at .05. Test statistics whose observed significance levels were less than or equal to .05 were taken to indicate significant relationship.

\section{FINDING AND DISCUSSION}

\section{Participants' oral language proficiency in accuracy, fluency and comprehensibility}

Table 3 shows the oral language proficiency of the third year students in terms of accuracy, fluency and comprehensibility.

Table 3:

Oral Language Proficiency

\begin{tabular}{lccccccc}
\hline \multicolumn{1}{c}{ Level } & \multicolumn{2}{c}{ Accuracy } & \multicolumn{2}{c}{ Fluency } & \multicolumn{3}{c}{ Comprehensibility } \\
& $\mathrm{F}$ & $\%$ & $\mathrm{f}$ & $\%$ & $\mathrm{f}$ & $\%$ \\
\hline 6Very High & 1 & 1.85 & 2 & 3.70 & 3 & 5.56 \\
5High & 6 & 11.11 & 2 & 3.70 & 4 & 7.41 \\
4Average & 11 & 20.37 & 16 & 29.63 & 18 & 33.33 \\
3 Moderately Low & 33 & 61.11 & 18 & 33.33 & 21 & 38.89 \\
2Low & 3 & 5.56 & 16 & 29.63 & 8 & 14.81 \\
1 Very Low & 0 & 0.00 & 0 & 0.00 & 0 & 0.00 \\
\hline \multicolumn{1}{c}{ Mean OLP } & (Moderately Low) & (Moderately Low) & (Moderately Low) \\
\multicolumn{1}{c}{ Overall OLP } & \multicolumn{7}{c}{3.3 (Moderately Low) } \\
\hline
\end{tabular}

The "moderately low" performance of the respondents in oral language proficiency as cited in the Table indicates that English as a Second Language among the students needed to be developed. It is a common observation that the proficiency of students in English subjects is affected by the use of their mother tongue, especially when they are conversing outside their English subject. It was found out that using mother tongue the overall English language proficiency level of students becomes critically low particularly in spelling and punctuation, verbal ability, and identifying errors is critically low. In the same token, it was found out that the foremost problem 
encountered by teacher-respondent is that students have poor communication skills which may be attributed to the following: big number of students in class; no practice of language speaking inside and outside the school; and there was no English speaking policy in the school.

\section{Compensatory Strategies Used in English as a Second Language}

Table 4:

Frequency of Compensatory Strategies used by the Participants

\begin{tabular}{lrr} 
& \multicolumn{1}{c}{ Frequency } & \\
\multicolumn{1}{c}{ Compensatory Strategies } & $\mathrm{n}=54$ & Percent \\
\hline 1. Switching to the mother tongue & 38 & 70.37 \\
2. Getting help & 22 & 40.74 \\
3. Using mim & 30 & 55.56 \\
4. Avoiding communication partially or totally & 27 & 50.00 \\
5. Selecting the topic & 27 & 50.00 \\
6. Adjusting the message & 35 & 64.81 \\
7. Coining words & 7 & 12.96 \\
8. Using circumlocution or synonym & 21 & 38.89 \\
\hline
\end{tabular}

The data revealed that code-switching was the most often used compensatory strategy in the respondents' attempt to repair communication breakdown and the least is coining words. Out of 54 respondents, 38 shifted to the use of mother tongue when their lack of vocabulary blocked them in their communication. Some switched completely to their mother tongue and used it simply to replace an unknown vocabulary or utterance. Further analysis of the data also showed that more participants were inclined to switch to their mother tongue during the interview than in the picture-cued narration. Thus, it seemed that the use of this compensatory strategy depended upon the kind of oral tasks the learners performed. Meanwhile, the second predominantly used oral compensatory strategy ( OCS) was adjusting or approximating the message which was according to (Nakatani, 2006) as an efficient strategy in conveying message.

Mime, on the other hand, has topped as third most predominantly used as OCS in oral production which is observable in the data. Hence, Mimes or gestures were more frequent in the picture-cued narration than in the oral interview. This strategy also "creates the optimal environment for neural plasticity, the ability of the brain to change that lead to production." (Blaydes \& Mitchell , 2012, p. 1).

The findings also showed that avoiding communication partially or totally and selecting the topic was the fourth most often used strategy in this study. These strategies were often used in oral interview that in picture cued narration. This is to say, that in oral interview its more intense, because the student needs to respond based on their point of view. Contrary, in picture-cued narration, the student will narrate base on what is being shown. Nevertheless, the participant had the tendency to falter as there was not much avoidance of communication in the picture-cued narration. Karbalaei and Taji ( 2014) found out that this strategy is well-utilized in non-native speakers ( NNEs) as they have to think vocabulary that suits in their answer, however, NNEs intend to stop 
answering a certain question because of their communicative competence is quite low (Dumlao \& Himmapan , 2018).

One of the least popular compensatory strategies was getting help. It is likely that the respondents were not at ease in getting help or assistance from others in trying to cope with their limitations in oral discourses. Lastly, using circumlocution or synonym shows more prevalent in the picture-cued narration than in the oral interview task. Thus, this means getting the meaning across by describing the concept or using a word that means the same thing. Meanwhile, finding reveals that coining words or making up new words to communicate desired ideas was the least frequently used compensatory strategy.

\section{Analysis of Extract}

The following sample excerpts illustrate the oral compensatory strategies utilized by the respondents in the two oral tasks:

\section{Communication Partially or Totally}

Analysis of Extract 1: Student no. 7 shows that the participant started to say something but he decided to stop and not to say something to avoid communication. This is an example of avoiding communication partially or totally.

\section{Excerpt 1: Student no. 7.}

L1: Ilocano

T: Hello, good morning, will you please tell something about yourself.

S: Hello ma'am, I'm Alvin Jake Binala, from here at Del Pilar. They say

I"msimple, intelligent, but . . but...

In this extract, it is observable that in communication process, particularly in Bilingual and Multilingual context, learners have a hard time to think promptly which would lead to impartial answer on a certain question. There were many factors that underpin in this view. One of those is "learner's anxiety ", as an anxiety hindered the communication process, wherein, learners cannot fully respond to certain question which would lead to short yet uncomprehensive answer.

\section{Switching to Mother Tongue}

In this excerpt, the participants cannot organize his idea. Analysis of Excerpt shows that the participant switched to his mother tongue because he could not think of the English term in expressing his ideas. The switch involved just one utterance in the whole sentence:

Excerpt 2: Student no. 7.

T: How do you describe yourself?

S: Simple ma'am.

T: Why do you say you are simple?

S: Couze. . . hindi ako pumu. . . masasabi ko. . . I'm telling myself. . . ah. . . uh. . . ahahaha. . . masasabiko sa aking sarili sapagkat hindi ako pumupunta sa mga gimik. . . hindi ako nakikipagsosyalan. [couze, I'm not ... I can tell... I'm telling myself... ah... uh..ahahaha... I can tell to myself because I am not use to going to gimic. . I am not use to be going classy.] 
The excerpt above illustrated code mixing, thus in non-native speaking context, this method was used as code-switching may be used as a defense mechanism in communication process. However, this way of mixing a word cannot convey the whole meaning, as each language has its own parameters of meaning (Heredia \& Altarriba, 2001), however, this would be also a beneficial in assessing the substance of learners answers.

\section{Alternative Construction}

The extract below shows that the participant tries to express his message in alternate acceptable construction wherein appropriate form or construction is known or not yet stable until the teacher gives the exact word. This is an example of adjusting the message.

\section{Excerpt 3: Student no. 7.}

$\mathrm{T}$ : What is your favorite subject? Why?

S: English and Chemistry ma'am. Couze, I like English becouze, I want to learn English.I want to become a good English speaker. And I want chemistry becouze, I want experimenting, I want to prove facts, I want to prove many... many. . . objects. I like to observe and so on. . .

$\mathrm{T}$ : You loved discovering things?

This can also be considered as getting help because the respondent is trying to ask for the correct term. Moreover, in this process, confirmation to students' answer is important, this will be done in inductive way of reconstructing learners' answers to fully achieve the expected answer of the question. Though it is personal view, however, expected answer should be observed.

\section{Adjusting or Approximating the Message}

In Excerpt 12, the word recognized as it was used in the context was an example of adjusting or approximating the message. The more appropriate word to replace this is noticed. Another word that was adjusted or approximated in its meaning is the word clothes. Clothes is a general term used to refer to any kind of clothing used in any particular occasion. The respondent used this word in place of coat which was considered more appropriate in the context. In Excerpt 12, the meaning conveyed was adjusted or approximated by the speaker through her use of the words boys for carpenters or painters and wet paint to mean the warning sign or notice placed on the chair and again the word bench for chair.

\section{Excerpt 12: Student no. 17}

\section{L1: Ilocano}

The man recognized that the chair was wet with paint and his clothes was stained. So he went to the dry cleaner to remove the stain. Moreover, the word bench in Excerpt 13 was used by the respondent in place of chair. This shows another example of adjusting or approximating the message. Bench is a term referring to a long seat for two or more people, usually made without a back or arms. The word was used by the participant to approximate the meaning of chair.

\section{Excerpt 13: Student no. 11}

\section{L1: Ilocano}

Explain: One day, two painters painted uh... uh... a bench and after painting it uh they placed a notice that it was newly painted. 
The clause the money abroad is expensive in Excerpt 15 was considered an approximation of the real message the respondent wanted to convey. When asked about what she meant by this during the post-conference, the respondent said the salary abroad is high.

\section{Excerpt 15: Student no. 1}

L1: Ilocano

T: What are your plans after graduation?

S: I will go abroad first because that"s what my parents and my relatives like. Another reason is the money abroad is expensive.

\section{Circumlocution or Synonym}

The answer of the participant in Excerpt 16 was an example of circumlocution. Instead of directly saying the adjective sociable, she used clauses I can go with others.

Excerpt 16: Student no. 20

L1: Ilocano

T: How do you describe yourself?

S: I am friendly. I can go with others easily.

\section{Use of Mime}

In the sample excerpt below, without saying the right words, the participants used hand gestures and body language to express what they meant. Though mimes were used, the listener understood the intended meanings of the speakers. This explains the importance of gestures or non-verbal communication in oral production. Another observation noted was the use of gestures simultaneous with the use of words to emphasize what they wanted to convey. The participants claimed that using mimes or gestures somehow helped them express the meaning and intention they wished to convey.

Excerpt 22: Student no. 26

L1: Ilocano

When the man noticed that his coat is painted, he go to the dry cleaner to...

(Performed the act of washing) his coat

\section{Getting Help}

In Excerpt 24, the participant used getting help by explicitly asking herself in Filipino the question, "Anonaangtawagdun?" (What is it?) However, in Excerpt 25, the nonverbal expression of the respondent, that is looking at the interviewer after hesitating to continue speaking was considered a getting help strategy.

Excerpt 24: Student no. 47.

L1: Ilocano

The painter put a... ano na ang tawag dun? (What is it?)... uh a card. The man put a sign that the bench is painted. 


\section{Coining Words}

In Excerpt 27, the word the participant coined to express her idea was balanced- headed. She coined the words balanced and head to create a description about herself which she thought was appropriate for the meaning she wanted to express. Apparently, the words she coined to describe herself seemed inappropriate. Perhaps she meant level-headed.

Extract 27: Student no. 25

L1: Ilocano

T: How do you describe yourself?

S: I"m a balanced-headed person ma'am.

\section{Relationship between Compensatory Strategies used and their Mother Tongue and Academic Performance in English}

Table 5:

Relationship between Compensatory Strategies Used by the Respondents and their Mother Tongue and Academic Performance in English

\begin{tabular}{|c|c|c|c|c|}
\hline \multirow[t]{2}{*}{ Compensatory Strategies } & \multicolumn{2}{|c|}{ First Language } & \multicolumn{2}{|c|}{$\begin{array}{c}\text { Academic } \\
\text { Performance in } \\
\text { English }\end{array}$} \\
\hline & Rho value & Prob. & Rho value & Prob. \\
\hline 1. Switching to the mother tongue & $0.18^{\mathrm{ns}}$ & 0.21 & $-0.40 *$ & 0.00 \\
\hline 2. Getting help & $0.28 *$ & 0.04 & $-0.0^{\mathrm{ns}}$ & 0.92 \\
\hline 3. Using mime & $0.00^{\mathrm{ns}}$ & 0.97 & $0.13^{\mathrm{ns}}$ & 0.35 \\
\hline $\begin{array}{l}\text { 4. Avoiding communication } \\
\text { partially or totally }\end{array}$ & $0.24^{\mathrm{ns}}$ & 0.07 & $-0.17^{\mathrm{ns}}$ & 0.23 \\
\hline 5. Selecting the topic & $0.38 *$ & 0.00 & $-0.42 *$ & 0.00 \\
\hline 6. Adjusting the message & $0.15^{\mathrm{ns}}$ & 0.28 & $-0.01^{\text {ns }}$ & 0.96 \\
\hline 7. Coining words & $-0.05^{\mathrm{ns}}$ & 0.72 & $0.08^{\mathrm{ns}}$ & 0.57 \\
\hline $\begin{array}{l}\text { 8. Using circumlocution or } \\
\text { synonym }\end{array}$ & $-0.33 *$ & 0.01 & $0.35 *$ & 0.01 \\
\hline
\end{tabular}

The table presents the relationship between compensatory strategies used by learners, their mother tongue and academic performance in English. The result indicates that learners employ oral compensatory strategies in their attempt to recompense their limitations in oral communication. Hence, teachers are encouraged to make the language classroom an avenue for students to learn how to learn with the use of language strategies.

The most popular compensatory strategies frequently employed by the respondents showed were code-switching. In formal classrooms, on the other hand, code- switching may be disfavored and may be considered an inefficient strategy (Tupas, 2004) most especially when students are strictly evaluated in terms of oral communication skills in English. However, code-switching may be valuable tool because "There is usually purpose and logic in changing languages. It is using the full language resources that are available to a bilingual usually knowing that the listener 
fully understands the code-switches" (Baker, 2006, p. 23). Tupas (2004) believes that code- switching "enables the students to cope with the communicative complexity of language use in society" (p. 64).Bearing in mind the social inference of code-switching, Mondada (2007) states that codes-witching is used by participants in order to organize multiple activities and their participation frameworks in distinct and orderly ways.

\section{Relationship between Compensatory Strategies and the Oral Language Proficiency (OLP)}

Table 6:

Relationship between Compensatory Strategies and the Oral Language Proficiency $(O L P)$ in Terms of Accuracy, Fluency and Comprehensibility

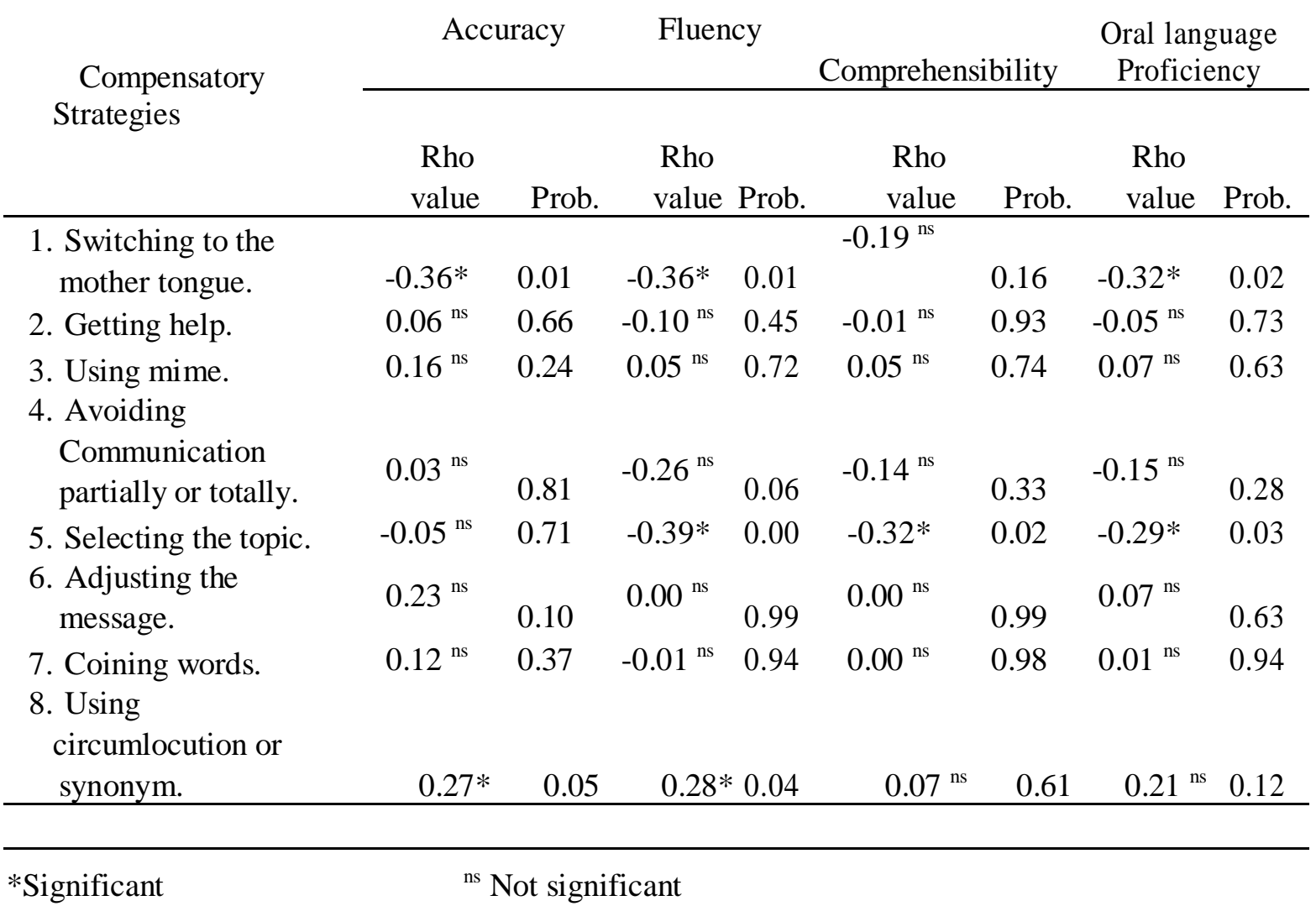

Compensatory Strategies and Fluency. Switching to the mother tongue and selecting topic are the compensatory strategies found to be significantly related with fluency in oral reading. The correlation values of -0.36 and -0.39 with probabilities less than 0.05 reveal further that the respondents who were more fluent in oral reading have lesser tendency to switch tongue and select topics as compared to those with less fluent in oral reading. In addition, the correlation value of 0.28 with probability 0.04 also reveals a significant association with fluency in oral reading. The respondents who are more fluent used circumlocution or synonym more than those respondents who are less fluent in oral reading. Further, compensatory strategies used by the respondents such as getting help, using mime, avoiding communication partially or totally, adjusting the message and coining words were not significantly related with the respondents" fluency 
in oral reading with correlation values ranging from -0.126to 0.05 with probabilities greater than 0.05 .

Compensatory Strategies and Comprehensibility. The correlation value of -0.32 with probability 0.02 reveals that selecting the topic is significantly associated with the comprehensibility of the respondents. This implies further that the respondents who can comprehend better more frequently use the strategy of selecting the topic as compared to the others with lower comprehensibility level. On the other hand, the level of comprehensibility of the respondents in oral reading is not somehow significantly related with their use of compensatory strategies such as switching to the mother tongue, getting help, using mime, avoiding communication partially or totally, adjusting the message, coining words and using circumlocution or synonym with correlation values ranging from -0.19 to 0.07 with probabilities greater than 0.05 .

Compensatory Strategies and Oral language Proficiency. In general, Table 6 reveals that switching to the mother tongue and selecting the topic were strategies used that were significantly associated with the oral language proficiency of the respondents. The correlation values of -0.32 and -0.29 with probabilities less than 0.05 , respectively, further imply that the respondents with higher oral language proficiency are less inclined to switch to the mother tongue and select the topic as compared to those with lower oral language proficiency.

The correlation values ranging from -0.15 to 0.21 with probabilities greater than 0.05 reveals no significant association between the oral language proficiency of the respondents and their use of compensatory strategies such as getting help, using mime, avoiding communication partially or totally, adjusting the message, and coining words. The above findings show that some compensatory strategies can be associated with the oral language proficiency of the students. In a recent study by Smith (2003) concluded that task type influences compensatory strategy used. Since the participants employed more compensatory strategies in decision-making tasks, it was suggested that decisionmaking tasks may elicit more compensatory strategies than jigsaw tasks.

\section{CONCLUSION AND SUGGESTION}

\section{Conclusion}

The present study affirms that learners employ compensatory strategies in oral communication. It reasserts that these strategies can help learners to overcome limitations in speaking. It also reaffirms the findings of previous studies that the type of compensatory strategies used is greatly influenced by the kind or oral tasks learners participate in. Further studies using a bigger population and other authentic oral communication tasks, however, are needed to provide additional solid support to the findings of the present investigation. It is also necessary to conduct studies correlating compensatory strategies and other oral language proficiency variables. On the basis of the findings of the study, it was found out that compensatory strategies used by the respondents such as getting help, selecting the topic and using circumlocution or synonym were significantly associated with their first language. Contrary to switching to the mother tongue that was negatively correlated with the accuracy level which indicates that respondents who had higher level of accuracy in oral reading had lesser tendency to switch to their mother tongue than those with lower level of accuracy. Meanwhile, using circumlocution or synonym was significantly associated with student's level of oral reading accuracy. The participants with higher level of accuracy in oral production more frequently use circumlocution or synonym. 
Further, Switching to the mother tongue and selecting topic were the compensatory strategies found to be significantly related with fluency in oral production. Selecting the topic was significantly associated with the comprehensibility of the respondents which implies that the respondents who can comprehend better more frequently use the strategy of selecting the topic as compared to the others with lower comprehensibility level.

In general, switching to the mother tongue and selecting the topic were strategies used that were significantly associated with the oral language proficiency of the respondents. The respondents with higher oral language proficiency are less inclined to switch to the mother tongue and select the topic as compared to those with lower oral language proficiency.

\section{Suggestion}

Based on the findings of the study, a remedial reading program may be created to increase the proficiency level of the students. English teachers are encouraged to give reading, listening and speaking exercises to students to enhance their skills.

Compensatory strategies used during the oral interview and picture-cued tasks, such as switching to the mother tongue and selecting the topic, are ways by which students can fully express themselves; however, teachers should discourage too much use of these strategies. Avoiding the use of compensatory strategies can serve as a venue for better oral reading performance of the students. Similar studies should be undertaken to include other variables such as school and environment factors that may affect the oral production of the students. 


\section{REFERENCES}

Blaydes, J. \& Mitchell, D., (2012). How exercicebenefits the brain: Learning through movement and music. Retrieved from http://www.humankinetics.com/excerpts/excerpts/learn-how-exercise-benefitsthe-brain

Baker, C. (2006). Foundations of bilingual education and bilingualism. USA: Multilingual Matters Ltd.

Dumlao, R., Himmapan K. ( 2018). Fostering Undergraduate communicative competence through Classroom-based instruction in an EFL Classroom: Does mode of instruction play a role?. A. Razali( Ed.), Proceedings of the 12th international conference on English language teaching, pp. 109-132. Universiti Putra Malaysia

Heredia, R. R., \& Altarriba, J. (2001). Bilingual language mixing: Why do bilinguals code-switch?.Current Directions in Psychological Science, Volume 10 (5), pp. 164-168. http://dx.doi.org/10.1111/1467-8721.00140J

Karbalaei, A., Taji, T. (2014). Compensation Strategies: Tracking Movement in EFL Learners' Speaking Skills. Gist Education and Learning Research Journal, Volume 9, pp. 88-102.

Mondada, L. (2007). Bilingualism and the analysis of talk at work: Code-switching as a resource for the organization of action and interaction. In : Heller, M. (ed.). Bilingualism. A Social Approach.

Nakatani, Y. (2006). Developing an Oral Communication Strategy Inventory. The modern language journal, Volume 90 (2), pp. 151-168. doi: 10.1111/j.15404781.2006.00390.x

Oxford, R. L. (1990). Language learning strategies: What every teacher should know. Englewood Cliffs, NJ: Newbury House.

Poulisse, N. \& Schils, E. (1989). The Influence of Task- and Proficiency-Related Factors on the Use of Compensatory Strategies: A Quantitative Analysis. Language learning, Volume 39 (1), pp. 23-45. https://doi.org/10.1111/j.14671770.1989.tb00590.x

Smith, B. (2003). The use of communication strategies in computer-mediated communication. System, Volume 31 (1), pp. 29-53. doi: 10.1016/S0346251X(02)00072-6 